Editorial

\title{
Resilient Civil Infrastructure under Dynamic Loadings 2020
}

\author{
Xing Ma $\mathbb{D}^{1},{ }^{1}$ Nawawi Chouw $\mathbb{D},{ }^{2}$ Mohamed ElGawady $\mathbb{D}^{3},{ }^{3}$ Songye Zhu $\mathbb{D}{ }^{4}$ \\ and Xiaonong Guo iD 5 \\ ${ }^{1}$ UniSA STEM, University of South Australia, Adelaide, Australia \\ ${ }^{2}$ Department of Civil and Environmental Engineering, The University of Auckland, Auckland, New Zealand \\ ${ }^{3}$ Department of Civil, Architectural and Environmental Engineering, Missouri University of Science and Technology, \\ Rolla, MO, USA \\ ${ }^{4}$ Department of Civil and Environmental Engineering, The Hong Kong Polytechnic University, Hong Kong, China \\ ${ }^{5}$ Department of Structural Engineering, Tongji University, Shanghai, China
}

Correspondence should be addressed to Xing Ma; xing.ma@unisa.edu.au

Received 28 July 2021; Accepted 28 July 2021; Published 17 August 2021

Copyright ( $\odot 2021$ Xing Ma et al. This is an open access article distributed under the Creative Commons Attribution License, which permits unrestricted use, distribution, and reproduction in any medium, provided the original work is properly cited.

Infrastructural systems are important components in the modern society. The design and construction of resilient civil infrastructures is an effective way to reduce or even avoid large economic losses due to the downtime of the infrastructure after a strong natural or manmade hazard. Following the 2018 Special Issue on resilient civil infrastructures, this 2020 Annual Issue addresses the challenges and emerging problems in the research area of resilient infrastructural systems under dynamic loadings, e.g., wind, traffic, tsunamis, and earthquakes.

After a rigorous reviewing process, eight papers have been finally selected for publication. Three papers address the seismic behavior of structures and structural joints including "Seismic Performance Analysis of Self-Centering Concentrically Braced Steel Frame Structures" by E. Xiong et al., "Seismic Response Study of Tunnels Running underneath a Subway Station in Parallel" by F. Sun et al., and "Seismic Behavior of Hybrid Frame Joints between Composite Columns and Steel Beams" by L. Chu et al. The impact resistance of a honeycomb shelter was studied in "Antipenetration Performance of Honeycomb Shelter under Two Repeat Projectile Strikes" by Q. Wang et al. Two papers entitled "Vibration-Isolation Performance of a Pile Barrier in an Area of Soft Soil in Shanghai" by X. F. Ma et al. and "Analysis of Lateral Dynamic Response of Caisson Foundation in Layered Clayey Soils considering Scour-Hole Dimensions" by W. Tu et al. investigate the soil-foundation interactional responses. Vehicle-induced vibration is studied in "Dynamic Reliability of Continuous Rigid-Frame Bridges under Stochastic Moving Vehicle Loads" by N. Lu et al. Finally, L. Wang et al. present a study on "Transmitting Characteristics of Seismic Motion in Super-Deep Overburden Layer Ground.”

We hope that the publication of the Special Issue will address some of the current challenges and stimulate further research in the related field.

\section{Conflicts of Interest}

The Guest Editors of this Special Issue declare no conflicts of interest.

Xing $\mathrm{Ma}$

Nawawi Chouw Mohamed ElGawady

Songye Zhu

Xiaonong Guo 